\title{
Research on the Optimum Population Scales of Counties in the Context of Sustainable Development --A case study of Lushan County
}

\author{
Na AN* , Tongji University, China \\ Binman YANG, Politecnico di Torino, Italy
}

\begin{abstract}
Population sustainability is an essential aspect of regional sustainable development strategies. However, sustainable development of population is currently focused on large-scale areas such as municipalities or cities. Still, attention is inadequate to the small-scale population sustainable development of counties. Under such circumstances, this paper intends to construct a model that can calculate the optimum population in the county based on the concept of sustainable development, selecting three effective systems: ecological, social, and economical to delineate the upper limit of optimum population development from multiple factors, and analysing the optimum population capacity of Lushan County from 2009 to 2019. At the current stage, the optimum population of Lushan County is smaller than the current population and is in a state of population overload and overpopulation. This paper will make recommendations on controlling population growth and increasing the capacity of an optimum population, improving the quality of land resources to increase the socially optimum population, strengthening the restoration of ecosystems to maintain an ecologically optimum population, increasing the efficiency of industries to improve economic and demographic support, and insisting on the coordinated development of people, economy, and resources. The concept of sustainable development is integrated into the strategy of sustainable population development.
\end{abstract}

\section{Keywords}

sustainable development, optimum population, optimum population-scale, Lushan County

With the accelerated urbanisation process in China, the urbanisation rate in China has increased rapidly, from $13.26 \%$ in 1953 to $63.89 \%$ in 2020 . While rapid urbanisation has contributed to the sustained and rapid development of the national economy, it has also brought about the transfer of a large amount of labour from the rural areas to the cities. Because of the complex demographic situation in China, such as the vast population foundation and rapid population growth rates, the scale of the population needs to be formulated to avoid many problems of uneven population distribution. A large population can bring congestion, lack of resources, and employment difficulties in the region. An undersized population will make the population hollow and aging, inadequate infrastructure supply, and regional social development in the township. It is also bringing about contradictions between population, economy, resources and environment, which not only puts enormous pressure on natural resources and the environment but also impedes the economic development and social progress of the township and poses a hidden danger that cannot be ignored for the healthy and sustainable development of the region. Based on the above, there is a need to maintain an optimum population-scale while preserving the 
stability of the regional system and maintaining the sustainable use of resources, thereby promoting sustainable regional development.

Since sustainable development was proposed in 1987, the people-centred approach has been an essential concept in sustainable development. A series of policies and initiatives have been implemented worldwide. For instance, the United Nations has declared 11 July each year as World Population Day to remind us that population issues are closely linked to achieving sustainable development goals. The Third International Conference on Population and Development (ICPD) held in 1994 recognised population issues as one of the elements of sustainable development. That population is an intrinsic part of development, forming a consensus that "population is essentially a development issue" (Sadik, 1997). China also considers sustainable population development as an essential aspect of its sustainable development strategy. The concept of sustainable development and the concept of human development as the core of development, which emphasises the focus on the capacity of nature to sustain human economic and social development, were proposed in the study on the theory and practice of integrated social development pilot zones in China(Meng, 2015). To a certain extent, these policies have provided new guidance for sustainable population development.

Based on the study of sustainable development theory and the theory of demographic requirements, this paper takes Lushan County in Ya'an City as an example to construct a framework for calculating the township's optimum population in the context of sustainable development at the small-scale county level. The paper also analyses the primary levels of the system and the main demographic elements in ecological, social and economic perspectives. This paper intends to propose countermeasures for sustainable population development in counties of China and provide a scientific basis for future regional population migration, population redistribution policies and population and economic development planning based on an understanding of the actual situation of population pressure.

\section{Research overview}

\subsection{Related concepts}

\subsubsection{Sustainable development}

Sustainable development is articulated in Chinese as the harmonious and coherent development of nature, economy and society, requiring that the needs of the present are met without compromising the interests of future generations. In the English context, it is interpreted as economic progress in a context that does not harm ecosystems. Sustainable development, as mentioned in Our Common Future, is "development that meets the needs of the present without jeopardising the needs of future generations." The concept of sustainable development has been defined by many scholars from different perspectives (Table 1).

Table 1 Concepts of sustainable development from different perspectives. Source: Self-drawn.

\begin{tabular}{ll}
\hline Aspect & Definition \\
\hline Natural & $\begin{array}{l}\text { Sustainable development is the search for an optimal ecosystem that supports ecological } \\
\text { integrity and realises human aspirations to sustain the human condition(Forman, 2015). }\end{array}$ \\
Social & Population growth tends to be balanced; economic stability, political stability and social
\end{tabular}


development are social development.

Economic Sustainable development is about maximising economic development benefits while maintaining the quality of natural resources and the services they provide(Cao, 1999).

Environmental They are protecting and enhancing the productive and renewal capacity of environmental systems.

Ecological The search for an optimal ecosystem that supports ecological integrity and fulfils human aspirations for a sustainable human existence.

Technology Shift to cleaner, more efficient technologies, as close to zero-emission or closed process methods as possible, with the least likely energy consumption and other natural resources.

From different perspectives, the concept of sustainable development is concerned with the correct handling of the relationship between people and nature and the coordination of the links between population, environment, and economy. As a complex giant system, sustainable development is represented by three major aspects: ecological, economic, and social sustainability. Ecologically sustainable development is the prerequisite and condition, sustainable economic development is the driving force and foundation, and socially sustainable development is the purpose and destination. (Ge\&Li, 1999)Therefore, this paper takes the connotation of sustainable development as the foundation and takes ecological, economic and social sustainability as the main factors limiting moderate development to calculate the optimum population scale.

\subsubsection{Optimum population}

Optimum population refers to the ideal number of people in a country or region. The English dictionary is interpreted as the optimal population size in terms of ecological sustainability and carrying capacity. The concept of the optimum population has a long history, tracing back to Plato's proposal for the ideal number of citizens. The relationship between population growth and the capital economy by Adam Smith(Peng, 1987) and the population principle by Malthus(1992) laid the foundations for the birth of the optimum population. The term "optimum population" arose from the British economist Edwin Cannan's theory of moderate population, which highlighted the amount of population that maximised the industry returns, followed by the work of Kunt Wicksell(1910) A.M. Carr-Saunders(1922), and A.M. Alcott(1922). Alfred Sauvy and others expanded the field of research on modest populations by including population growth rates in calculating modest populations(Renström\& Spataro, 2011).

Compared with the actual population, the optimum population can better reflect the production and quality of life. It can also measure the capacity of resources in the region to accommodate the people and promote the balanced development of the population's social, economic, ecological, and other resources. With the further study of optimum population, the connection between optimum population and sustainable development has become increasingly intense(Zhang, 2011); the research elements of the optimum population have developed from static factors to the study of dynamic factors that change over time(Liu, 2000). The research field has expanded from a single economic factor to multi-factor aspects such as social resources(Shi, Li \&Zhao, 2010), land resources (Pimentel, Giampietro \& Bukkens, 1998), and ecological resources(Pimentel et al., 1998). The research objectives have also covered the urbanisation development analysis, total carrying capacity, etc. It is the objective and goal of this paper to expand the coverage of the optimum population further. 
At present, there are three main methods for measuring optimum population: the ecological footprint method(Yang, 2019), the P-E-R model(Liu, 2007) and the Possible-Satisfaction (P-S) model(Wang, 2021). The ecological footprint method can quantitatively measure the resource consumption demand of a specific population. Its indexes consider the impact of human activities on natural ecosystems, reflecting the ecological constraints on the moderate people. Still, it neglects the influence of economic and social factors. Therefore, this paper uses the improved ecological footprint model, considers social and economic ecological elements and determines the weights of each indicator by the entropy method, to make up for the shortcomings of the original ecological footprint method and avoid excessive subjectivity.

\subsubsection{The Importance of Moderate Population for Sustainable Development}

As a humanist, open-minded and complex system, Agenda 21 in China also pointed out that "sustainable development is people-centred and promotes the spirit of the human subject to promote the harmony between human society and nature". The Third Plenary Session of the 16th CPC Central Committee then proposed: "Establishing a people-oriented, integrated, coordinated and sustainable development concept". These proceedings further illustrate the role of the population in the sustainable development system as a fundamental component of the basic design of sustainable development. The ultimate key to a functioning sustainable development system lies in people and how they can contribute to the harmonious development of people and the environment through their activities, labour productivity, and the sustainable development of the eco-social-economic system. The significance of population as an essential part of sustainable development is focused on population indicators (Table 2), which indicates that population is an integral part of sustainable development and is necessary for the coordination of human, social, economic and environmental relations. An optimum population will facilitate the implementation of sustainable development policies.

Table 2 Population index in sustainable development index. Source: Self-drawn.

\begin{tabular}{|c|c|}
\hline Index system & Definition \\
\hline UN Human Development Index & $\begin{array}{l}\text { Life expectancy at birth, educational achievement, the standard of } \\
\text { living }\end{array}$ \\
\hline UN CSD Indicator System & The unemployment rate, poverty index, GDP per capita \\
\hline $\begin{array}{l}\text { New World Bank Country Wealth } \\
\text { Indicators }\end{array}$ & Human capital (type of wealth), human organisation, human scale \\
\hline EU Sustainability Indicators & $\begin{array}{l}\text { Improve population quality and pay attention to population } \\
\text { changes }\end{array}$ \\
\hline $\begin{array}{l}\text { China Sustainable Development } \\
\text { Indicators }\end{array}$ & $\begin{array}{l}\text { Social development indicators such as population, population } \\
\text { density, population growth rate, etc. ( } \mathrm{He}, 1996)\end{array}$ \\
\hline US Sustainability Strategy & Proposing population goals for sustainable development \\
\hline
\end{tabular}

\subsection{Framework}

In response to the problems of insufficient data, single factors and large regions in the calculation of moderate population in the context of sustainable development at the present stage, this paper attempts to build a multi-factor and multi-factor framework for the analysis of the middle population in the county from the connotation of sustainable development - ecological, social and economic aspects - starting 
from the small-scale county level, and taking Lushan County as an example. In this paper, we will comprehensively analyse the carrying population and optimum population of Lushan County from 20092019 by using the natural growth method, grey prediction method and linear regression method to predict the future population scale, and then explore the development model of the optimum population in county-level with population accuracy and rationalisation, to guide the regional population towards dynamic and sustainable renewal and form a benign regional population structure.

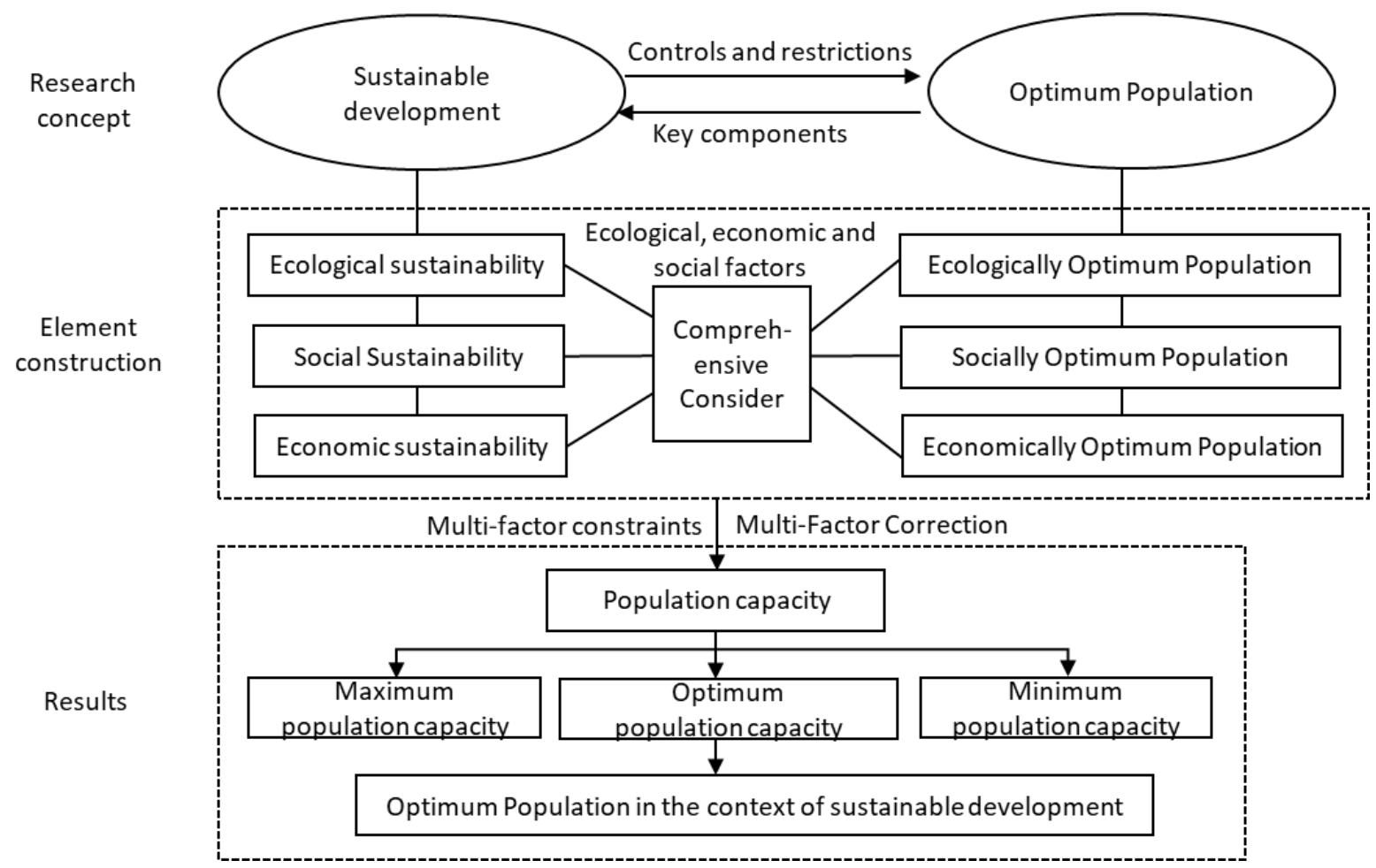

Figure 1. Optimum Population Scales framework of Counties in the context of sustainable development. Source: Self-drawn.

\section{Case study region and research methods}

\subsection{Study region}

Lushan County is located on the west side of the Sichuan Basin, northeast of Ya'an City, with 1,166 square kilometres. The overall ecological base is quite good. The terrain is complex, with high, middle and low mountains and river valley terraces widely distributed. The mountain belt dominates the landscape, which accounts for about $73 \%$ of the total area, and the high mountain and low mountain belts and flat dams account for about $27 \%$ of the entire region. The city's annual average temperature is $15.7^{\circ} \mathrm{C}$, the average yearly precipitation is $1077.3 \mathrm{~mm}$, the annual average sunshine hours is 837.1 hours, the rainfall is abundant, the seasons are distinct, the frost-free period is long, the sunshine is low. The climate is characterised by sufficient heat, abundant precipitation, high humidity and intense sunlight. The city has a resident population of 119,800 , of which 44,300 are urban, and 66,200 are rural, with an urbanisation rate of $40.8 \%$ and a natural population growth rate of $-4.1 \%$. The county is rich in land resources, with an ecological space area of 843.22 square kilometres, accounting for $72.33 \%$ of the county's total area, and an agricultural space area of 284.49 square kilometres, accounting for $24.40 \%$ of the county's total area. The location of urban space is 38.09 square kilometres, accounting for $3.27 \%$ of the county's total area. 
The current land utilisation rate is low, and the overall exploitable potential is high. In contrast, the land utilisation rate and productivity level are shallow, land utilisation is greatly restricted, and the economic benefits of land use are low.

\subsection{Research methodology}

\subsubsection{Ecologically optimum population measurement}

This paper uses an improved ecological footprint to calculate the ecologically optimum population. The ecological footprint model was first proposed by William E. Rees and M. Wackernagel(Wackernagel\& Rees, 1998; Wackernagel\&Yount,1997), and its primary function is to quantify the area of land required for human consumption of resources and cleaning of waste at a given population and economic scale. The ecological footprint is bipartite, reflecting the size of a given population's impact on the environment under certain conditions and consumption levels and the number of people supplied with environmental resources. The ecological footprint is divided into ecological (ecological occupation) and ecological carrying capacity (natural supply). The ecological footprint converts the differences in land productivity of different environments in different regions through equilibrium and yield factors. To address the problems of old data, single function and simple factors, this paper constructs an improved ecological footprint model by correction of data, expansion of a land function, localised processing of equilibrium and yield factors and the addition of time continuity(Fang, 2015; Huang, Zhang\&Jiang, 2008; Wackernagel, Monfreda\& Erb, 2004), with the formula as follows.

$$
\begin{aligned}
& E F_{G}=E F+E F n+E F w=\sum_{i=1}^{n} \frac{C i}{E P i} E Q i+\frac{Q C}{A C} E Q i+\frac{W}{P} \times \gamma w \\
& E C_{G}=E C+E C w=\sum_{i=1}^{n}(A \mathrm{i} E Q i Y F i) \times(1-12 \%)+0.4 \times \psi \times \gamma \times \frac{Q}{P} \\
& E D^{\prime} / E R^{\prime}=E F_{G}-E C_{G}
\end{aligned}
$$

Where,

EFG refers to the improved ecological footprint,

EF refers to the conventional ecological footprint,

EFn refers to the pollutant ecological footprint,

EFW refers to the ecological water footprint,

ECG refers to the improved ecological carrying capacity,

EC refers to the conventional ecological carrying capacity,

ECW refers to the water ecological carrying capacity,

ED' refers to the enhanced ecological deficit and,

ER' refers to the improved ecological surplus.

The optimum population formula based on the improved ecological footprint is expressed as(Pan, 2013).

$$
P_{\mathrm{E}}=\frac{E C_{G}}{\mathrm{ef}_{G}}
$$

Where,

Pe represents the ecologically optimum population of the region, and 
ECG represents the improved ecological carrying capacity,

efG represents the improved ecological carrying capacity per capita.

\subsubsection{Economically optimum population measurement}

In this paper, GDP is used for calculating the economically optimum population. As the primary representation of regional economic development, capital and technology, GDP reflects the level of regional economic development and industrial development, and GDP is closely related to the sustainable development of the economy and society(Guo, 2015). Therefore, this research uses GDP to represent the economic resources situation. The economic carrying population specifically refers to the number of people that can be carried under a certain level of economic development correspondingly. The specific calculation method is as follows:

$P_{\mathrm{GDP}}=\frac{T_{P}}{T_{G D P}} \cdot R_{P}$

Where,

PGDP represents the economically optimum population of the region, and

TP represents the national population size,

TGDP stands for Gross Domestic Product,

RP stands for Regional Gross Product.

\subsubsection{Calculating the socially optimum population}

This paper uses land resources to calculate the socially optimum population. As the material basis necessary to sustain human social development, land resources are essential for social sustainability. Still, their scarcity, non-renewability and finiteness limit the growth of the social population. This paper adopts arable land resources as a representative of land resources. By calculating the number of people that a region can carry under certain arable land restrictions, the specific formula is as follows:

$P_{\mathrm{CL}}=\frac{T_{P}}{T_{C L}} \cdot R_{C L}$

Where,

PCL represents the socially optimum population of the region, and

TP represents the national population,

TCL represents the national arable land area,

$\mathrm{RCL}$ represents the area of arable land in the region.

2.2.4. The formula for measuring the optimum regional population

In connection with the above procedures and the definition of optimum population under sustainable development, the recipes for calculating moderate population are defined as follows:

$S_{\mathrm{OP}}=0.39 P_{E}+0.28 P_{C L}+0.33 P_{G D P}$

Where,

SOP represents the optimum regional population, 
PE represents the ecologically optimum population of the region, and

PCL represents the socially optimum population of the area, and

PGDP represents the optimum economic population of the region.

The coefficients are obtained by the entropy weighting method.

\section{Optimum population analysis of Lushan County}

\subsection{Ecologically optimum population in Lushan county, 2009-2019}

According to the ecologically moderate population (Figure 2), the ecologically optimum population in Lushan County rose rapidly during 2009-2019, showing a "fluctuating" state. From 46,892 in 2009 to 65,344 in 2019 , a rise of $39.3 \%$. The reasons are as follows: Firstly, the ecological footprint of Lushan County gradually declined between 2009 and 2019, from 227,096 hectares in 2009 to 136,165 hectares in 2019 , a decline of $40 \%$, although the ecological carrying capacity did not change much (down $15 \%$ ), with an ecological deficit of $-138,354.5 \mathrm{hm}^{2}$ in 2009 and $-60,926.8 \mathrm{hm}^{2}$ in $2019.60926 .8 \mathrm{hm}^{2}$, the ecological deficit has decreased by more than $55 \%$, and the degree of the ecological deficit is gradually decreasing. Secondly, since 2014, Lushan County has gradually halted the coal industry and reduced ecological footprint consumption in the county, which has led to a gradual improvement in the rural ecological environment, which has led to a gradual increase in the ecologically moderate population of Lushan County. However, due to the overall ecological deficit in Lushan County, the pressure brought by economic development far exceeds the ecological carrying capacity. The gap between the ecologically fit population and the actual population is the largest compared to the economically optimum population and the socially optimum population, with the optimum population being only one-third of the actual population in 2015.

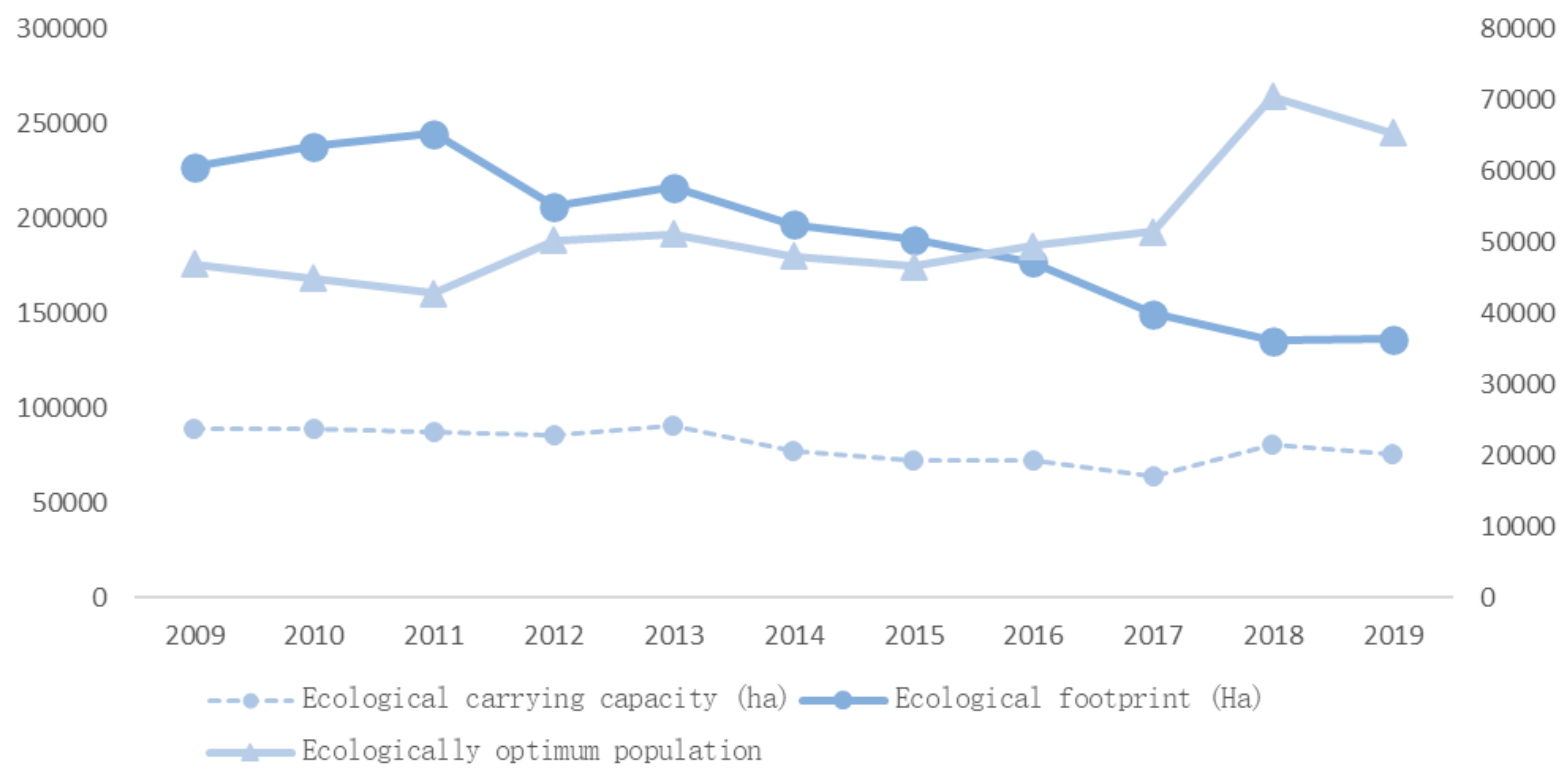

Figure 2. Ecologically optimum population in Lushan county, 2009-2019, Source: Self-drawn. 


\subsection{Economically optimum population in Lushan county, 2009-2019}

According to the economically optimum population (Figure 3), it can be seen that during the period 20092019, the economically optimum population of Lushan County fluctuated and changed dynamically, showing a slight overall upward trend, gradually rising from 61,239 in 2009 to 61,763 in 2019, an increase of $9.7 \%$. The reason for this is that between 2009 and 2019, Lushan County's GDP rose significantly, from RMB $159,664,000$ to RMB 474,217,000, a rapid increase of nearly twice as much as China's GDP growth rate $(184 \%)$ during the same period, indicating that Lushan County's economy is gradually rising and is relatively technologically developed. Resource utilisation rates have steadily increased, but the difference between the economically optimum population and the actual population was still huge, with the optimum population in calendar years being only about half of the existing population, indicating that although the economic level of Lushan County has risen, it still lags behind other regions, resulting in a mismatch between economic development and population growth and low economic efficiency.

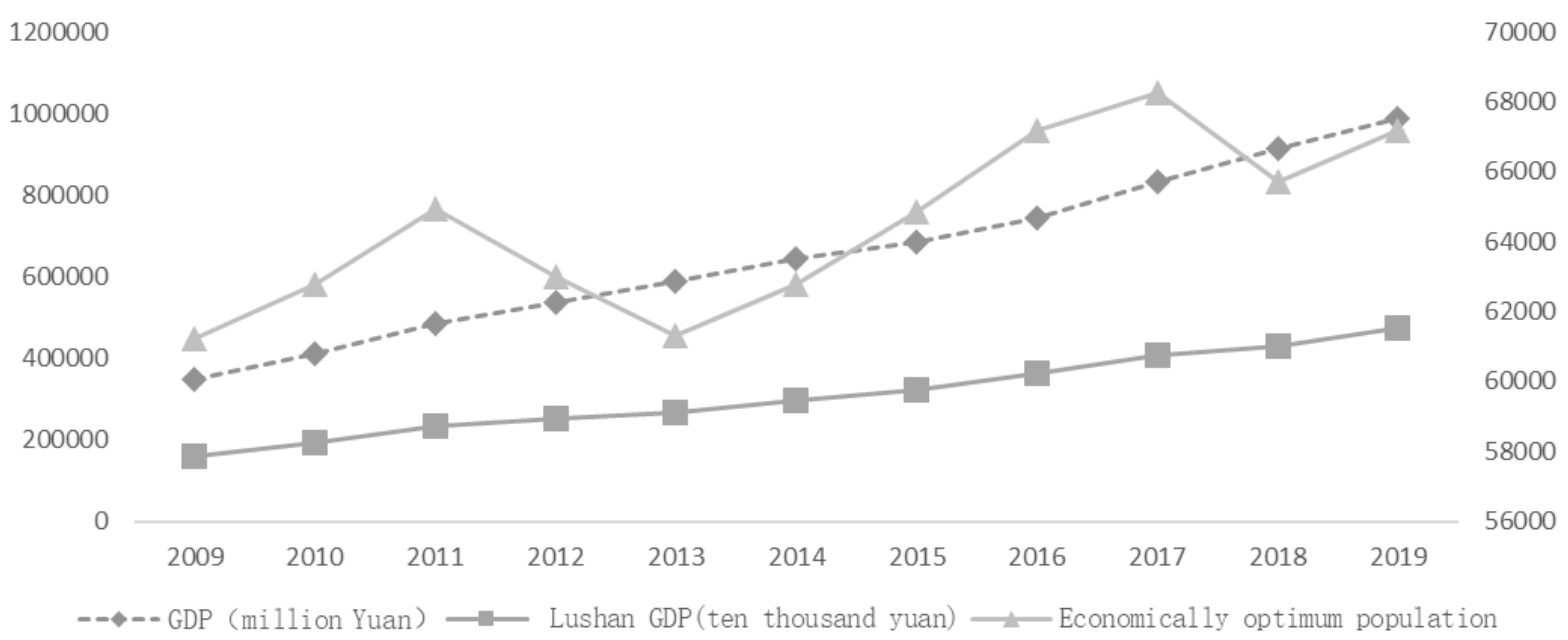

Figure 3. Economically optimum population in Lushan county, 2009-2019, Source: Self-drawn.

\subsection{Socially optimum population in Lushan county, 2009-2019}

According to the socially optimum population (Figure 4), the socially optimum population of Lushan County dropped significantly between 2009 and 2019, from 109,868 to 58,892, a decline of nearly 50\%, especially in 2017, showing a cliff-shaped decline, for the following reasons: One is that the area of arable land in Lushan County is gradually decreasing (-46.4\%), with a slight decrease from 2009 to 2016 and a sharp decline in 2017 leading to a reduction of land resources, which in turn affects the socially optimum population. The other is related to the Lushan earthquake in 2013, which may have affected land resources through the regional arable land area and arable land production. The gap between the socially optimum population and the actual population in Lushan County gradually became smaller from 2009 to 2012 , indicating that the quality of land resources in Lushan County was relatively good during this time, and the relationship between people and land was moderated. However, from 2013 onwards, the gap between optimum and actual populations has gradually increased, and land resources face the dilemma of quality deficiency and quantity reduction. 
--A case study of Lushan County

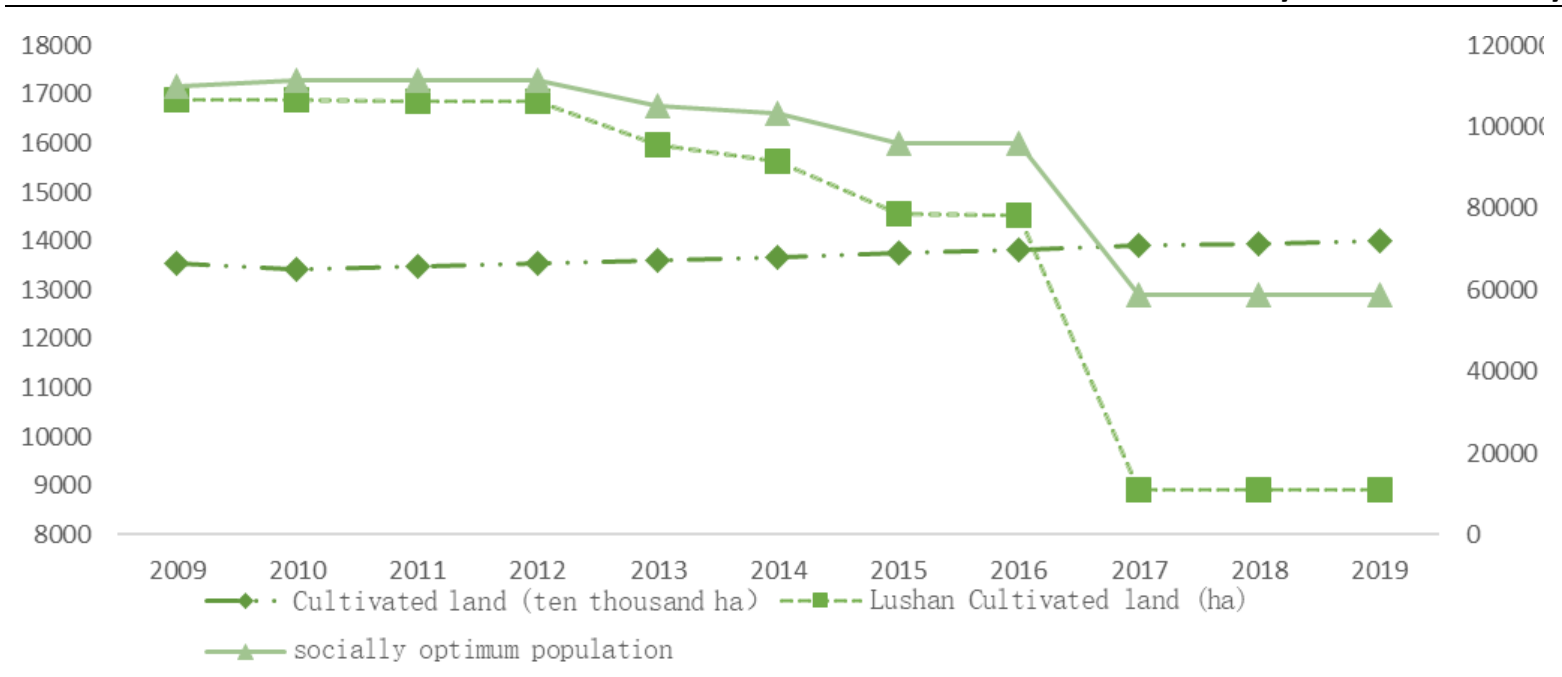

Figure 4. Socially optimum population in Lushan county 2009-2019, Source: Self-drawn.

\subsection{Analysis of the total optimum population in Lushan county, 2009-2019}

According to the optimum population of Lushan County from 2009-2019 (Figure 5), it can be seen that the total optimum population of Lushan County gradually decreased between 2009 and 2019, from 71,691 to 63,724 , a drop of nearly $11 \%$, with the most significant reduction in 2017 . From the changing trends of the social, economic and ecological optimum population of Lushan County, the optimum ecological population rose the most (39.3\%), followed by the economically optimum population (9.7\%). In comparison, the socially optimum population declined significantly $(-46.4 \%)$. The decline in the socially optimum population is much more significant than the increase in the ecologically and economically optimum population, indicating that the population growth due to ecological restoration and economic and technological upgrading in Lushan County cannot offset the population shrinkage caused by the decline in land resources, and that regional land development is significantly affecting the sustainable development of the region, and that the area is in an unsustainable state of development.

\section{0}

100000

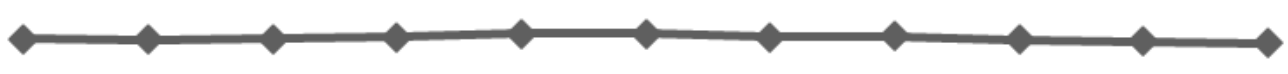

50000

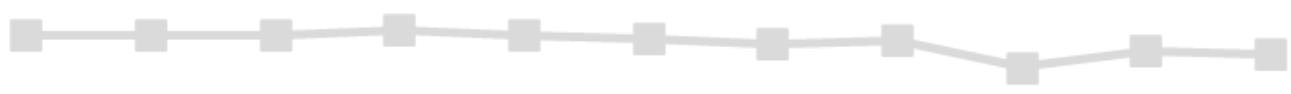

\section{(1)}

$-50000$

$\begin{array}{lllllllllll}2009 & 2010 & 2011 & 2012 & 2013 & 2014 & 2015 & 2016 & 2017 & 2018 & 2019\end{array}$

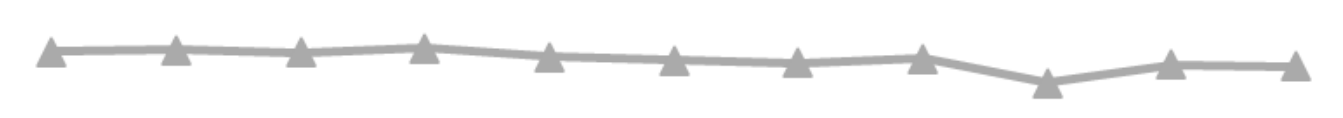

$-100000$

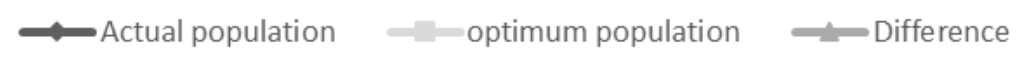

Figure 5. Total optimum population in Lushan county 2009-2019, Source: Self-drawn. 
Exploring the causes in more depth, this paper draws three conclusions:

Firstly, the significant reduction in the area of arable land in Lushan County has led to a shortage of land resources to meet the land resource gap caused by population growth.

Secondly, although green power has been implemented and low-carbon technology has been upgraded, Lushan County is still an industrial town with a high output value of secondary industries but few employed people (21.1\%) and a low output value of primary industries but still holding the majority of employed people (46.6\%), indicating that the processing and transformation rate of industries is not high, further affecting the optimum economic population.

Thirdly, the ecology of Lushan County has not yet been fully restored and is still in and will remain in a long-term ecological deficit, with poor sustainability of ecological development and ecological security not being optimistic. There is an urgent need to improve the quality of land resources, increase the efficiency of industries and rehabilitate the ecosystem, progressively increase the capacity of the moderate population and promote the sustainable development of the region.

\section{Conclusions}

The unified and coordinated production of economic development, land resources and ecological environment are the requirements of the theory of optimum population for sustainable development. The extensive use of the multi-factor and multi-angle study of the optimum regional population is an inevitable requirement for regional sustainable development strategies. In this paper, an ecologically optimum population, socially optimum population and economically optimum population scheme are constructed to calculate the optimum population scale of Lushan County under the constraints of the ecological, social and economic foundation of sustainable development. The results show that the optimum population in Lushan County from 2009 to 2019 is much smaller than the actual population. The region is in an unsustainable state, where regional land development significantly affects the region's sustainable development. The population growth from ecological and environmental restoration and economic and technological upgrading cannot compensate for the population shrinkage caused by the decline of land resources. The region is in an unsustainable state.

To further reduce the discrepancy between actual population and moderate population, two methods and strategies should be implemented by the Lushan County Government. The first is to control the population growth rate, control the population through eugenics, and improve people's quality and productivity. The second one is to increase the carrying capacity of the people.

Improving land quality can be achieved by protecting land resources, strictly defining red lines for arable land and stopping the indiscriminate cultivation of land. The improvement of industrial efficiency can be achieved by controlling the emission of pollutants, improving the efficiency of waste recycling, and promoting clean energy. The quality of the ecological environment can be enhanced by afforesting marginal farmland, designating protected areas and comprehensively improving the ecological environment. The ultimate goal is to increase the population scale, accelerate economic development, focus on ecological protection and rational use of resources for further sustainable development of Lushan County. 


\section{References}

Sadik, N. (1997). 'Women, population and sustainable development in South Asia', Journal of International Affairs, 147-168.

Meng, X. (2015). 'International experience and enlightenment of sustainable development strategy', Master thesis, Party School of the CPC Central Committee, China.

Forman, R. T. (1990). 'Ecologically sustainable landscapes: the role of spatial configuration', In Changing landscapes: An ecological perspective (pp. 261-278). Springer, New York, NY.

Cao, L. J. (eds.) (1999) Theory and method of sustainable development Evaluation. Beijing: Science Press. Ge, X. Q, \&Li, F. Q. (eds.) (1999) Knowledge Economy and Sustainable Development. Beijing: Social Sciences Academic Press.

Peng, S. J. (eds.) (1987) Introduction to Western Population Economics. Beijing: Peking University Press. Malthus, T. R., Winch, D., \& James, P. (1992). Malthus:'An Essay on the Principle of Population'. Cambridge university press.

Carr-Saunders, A. M. (1922). The population problem: a study in human evolution. Oxford: Clarendon Press.

Renström, T. I. , \& Spataro, L. (2011). 'The optimum growth rate for the population under critical-level utilitarianism', Journal of Population Economics, 24(3), 1181-1201.

Zhang, D. (2011). 'The sustainable development under the background of urban moderate populationscale research', Master thesis, Southwest Jiaotong University, China.

Liu, Y. L. (2000). 'Analysis of moderate population size and early warning in China's sustainable development', China Population, Resources and Environment,(S2), 97-99.

Shi, L., Li, D., \& Zhao, J. (2010). 'A method to estimate urban optimum population conditions: a case study of Xiamen, China', International Journal of Sustainable Development \& World Ecology, 17(4), 324328.

Pimentel, D. , Giampietro, M. , \& Bukkens, S. G. (1998). 'An optimum population for North and Latin America', Population and Environment, 20(2), 125-148.

Wang, C. L. , Cheng, S. J. , Zhu, Z. L. ,\& Wang, M. M. (2020). 'An analysis on the development of new urbanisation based on moderate population capacity: A case study of five prefecture-level cities in Ningxia', Chinese Agricultural Science Bulletin (07),151-157.

Li, X. X., \& Meng, M. (2017). 'Moderate population analysis of Jilin Province based on comprehensive carrying capacity', Chinese Journal of Applied Ecology(10),3378-3384.

Yang, J. C. , Wu, Q. F. , \& Li, S. L. (2019). 'Population and environment in Yunnan, Guangxi and Guizhou Rocky desertification area based on ecological footprint: a case study of Southwest Guizhou Province', Ecological Economy (10),136-142+190

Liu, Y. X. , Zhang, X. L. ,\& Lei, J. (2007). 'A preliminary study on a moderate population in Xinjiang', Journal of Arid Land Resources and Environment (05),35-40.

Wang, Y., Xie, Y. J., Liu, R. \& Zhang, H. (2021). 'Urban population prediction and resource allocation in Beijing, Shanghai, Guangzhou and Shenzhen cities', Acta Geographica Sinica (02),352-366. 
Ren, X. Y. (2001). 'The sustainable development of appropriate demographic theory', Master thesis, Central China regular university, China.

He, X. Y. (1996). 'Sustainable development index system', World Environment (01),11-13.

Wackernagel, M., \& Rees, W. (1998). 'Our ecological footprint: reducing human impact on the earth', (Vol. 9). New society publishers.

Wackernagel, M. , \& Yount, J. D. (1998). 'The ecological footprint: an indicator of progress toward regional sustainability', Environmental Monitoring and Assessment, 51(1), 511-529.

Fang, K. (2015). 'Footprint family: concept, type, theoretical framework and integration model', Journal of ecology (6), 1647-1659.

Huang, L. N. Zhang, W. X., Jiang, C. L. \& Fan, X. Q. (2008). 'Calculation method of water ecological footprint', Acta Ecologica Sinica (03), 1279-1286.

Wackernagel, M. , Monfreda, C. , Erb, K. H. , Haberl, H. , \& Schulz, N. B. (2004). 'Ecological footprint time series of Austria, the Philippines, and South Korea for 1961-1999: comparing the conventional approach to an 'actual land area'approach', Land use policy, 21(3), 261-269.

Pan, J. H. (2013). 'The measurement of the moderate ecological population in Lanzhou city with multiindex constraints', Population and Development (02),33-39.

Guo, L. Y. , Lei, M. , \& Liu, X. Q. (2015). 'Research on green GDP accounting based on energy value analysis method - an example of Shangluo City, Shaanxi Province', Journal of Natural Resources (09), 1523-1533. 